\title{
Assessment of ileal function by abdominal counting of the retention of a gamma emitting bile acid analogue
}

\author{
E H THAYSEN, * MARIANNE ORHOLM, T ARNFRED, J CARL, and P RØDBRO \\ From the Departments of Medical Gastroenterology, Clinical Chemistry, and Clinical Physiology, Aalborg \\ Regional Hospital, Denmark
}

SUMMARY In eight patients without gastrointestinal complaints and 30 patients with various gastrointestinal disorders ileal bile acid conservation was assessed by oral administration of ${ }^{75} \mathrm{Se}$ 23-selena-25-homocholic acid (SeHCAT) followed by abdominal gamma counting (SeHCATtest). The results of the test correlated fairly well with the clinical features and with the $\left[1-{ }^{14} \mathrm{C}\right]$-cholylglycine breath test including faecal ${ }^{14} \mathrm{C}$ measurements (breath test). Of the two bile acid absorption tests the new is perhaps the more sensitive and is the one most easily performed.

Bile acid malabsorption is usually the result of terminal ileopathy, but it may also occur in the absence of conventional ileal disease. The latter applies, for example, to diseases associated with excess small gut luminal flow such as secretory, osmotic, and postvagotomy diarrhoea, where the abnormal detergent loss is an epiphenomenon. Furthermore, it also applies to the so-called idiopathic bile acid diarrhoea; ${ }^{1}$ this disorder shows no abnormal gastrointestinal signs apart for an unexplained moderate loss of bile acid resulting in cholegenic enteropathy that is promptly and permanently relieved by long-term cholestyramine therapy. In clinical practice, bile acid malabsorption is detected by means of the trihydroxyl bile acid absorption tests, which, in fact, represented the most sensitive assays of inflammatory disease of the distal ileum. ${ }^{23}$ Counting radioactivity in the stool is inconvenient, and, as suggested by Hofmann, ${ }^{4}$ a gamma-labelled bile acid which could be detected by external counting might greatly facilitate the technique.

Recently Amersham International Ltd has produced the taurine conjugate of ${ }^{75} \mathrm{Se} 23$-selena-25homocholic acid (SeHCAT) which is absorbed from the gut and secreted into bile at the same rate as ${ }^{14} \mathrm{C}$

* Address for correspondence and reprints: Eigil Hess Thaysen, Department of Medical Gastroenterology, Aalborg Regional Hospital, POB 561. DK 9100 Aalborg. Denmark.

Received for publication 26 January 1982 cholic acid. ${ }^{5}$ We have had the opportunity of making a preliminary evaluation of this compound using abdominal gamma counting (SeHCAT-test) to assess bile acid conservation in various disorders. In order to evaluate the results achieved the $\left[1-{ }^{14} \mathrm{C}\right]-$ cholylglycine breath test including ${ }^{14} \mathrm{C}$ measurement in stool $^{36}$ (breath test) was performed simultaneously with the SeHCAT-test.

\section{Methods}

PATIENTS

Those studied included 38 patients, 26 women and 12 men, with a mean age of 47 years (22-71 years).

Excess bile acid loss was not suspected in eight patients with no history of gastrointestinal disease and in four patients with ulcerative colitis. In six patients with rather extensive resection or inflammation of the distal ileum, bile acid malabsorption was marked, whereas it was suggested in 20 patients with chronic diarrhoea from various causes.

5-9 $\mu \mathrm{Ci}^{75} \mathrm{SeHCAT}$ (Amersham, SCQ.3415) and approximately $8 \mu \mathrm{Ci}\left(1-{ }^{14} \mathrm{C}\right)$-glycocholic acid (Amersham, CFA.492) were administered orally with a liquid test meal to the fasting patient. The ${ }^{14} \mathrm{C}$ breath test, which is in routine use in this department, was performed as described earlier, ${ }^{36}$ but special precautions were taken to measure ${ }^{14} \mathrm{C}$ in stool containing various amounts of this isotope and ${ }^{75} \mathrm{Se}$.

In the SeHCAT-test the initial count rate (' $100 \%$ 
value') was measured three hours after the intake of isotope (day 0 ), with the patient lying supine below an uncollimated large field-of-view gamma camera (Ohio Nuclear Sigma 410). The distance from the couch to the gamma camera crystal (diameter 51 $\mathrm{cm}$ ) was maintained at $44 \mathrm{~cm}$, and the crystal was centred over the middle of the abdomen. The activity of ${ }^{75} \mathrm{Se}$ was measured in a $20 \%$ window around the 265 and $280 \mathrm{keV}$ photon peaks. The background was evaluated for 300 seconds immediately before and after the patient was measured, which was also for 300 seconds. The average background count rate (approximately 200 counts per second) was subtracted from the patient count rate to give the net count rate (cps). After the second examination, which was performed on day 5 , the net count rate day 5 was expressed as a percentage of the net count rate at day 0 - that is,

$$
\% \text { retention }=\frac{\text { net count day } 5}{\text { net count day } 0} \times 100 \text {. }
$$

Typically, the initial count rate for a $8 \mu \mathrm{Ci}$ dose under these conditions was $5000 \mathrm{cps}$, equivalent to approximately $30000 \mathrm{cps}$ in the entire spectrum. With our gamma camera there was no measurable dead time loss before three times the maximal dose which was used in the patients.

\section{Results}

From Table 1 it appears that out of the eight patients without gastrointestinal complaints five only, serving as controls, had negative breath tests. In order to further increase the control material four patients with ulcerative colitis and no evidence of backwash ileitis were also included. On the basis of

Table 1 Results of cholyl-glycine breath test and ${ }^{75} \mathrm{SeHCAT}$ test in relation to primary classification of 38 patients

\begin{tabular}{|c|c|c|c|}
\hline & \multirow{2}{*}{$\begin{array}{l}{\left[1-{ }^{14} \mathrm{C}\right] \text {-cholyl- }} \\
\text { glycine breath } \\
\text { test }\end{array}$} & \multicolumn{2}{|c|}{$\begin{array}{l}{ }^{75} \text { Se retention } \\
\text { day } 5(\%)\end{array}$} \\
\hline & & Range & Median \\
\hline Controls $(n=8)$ & $\begin{array}{l}\text { Negative }(n=5) \\
\text { Borderline }(n=3)\end{array}$ & $\begin{array}{l}40-82 \\
13 \\
31,33\end{array}$ & 44 \\
\hline Ulcerative colitis $(n=4)$ & Negative $(n=4)$ & $37-82$ & 59 \\
\hline Chronic diarrhoea $(n=20)$ & Negative $(n=8)$ & $\begin{array}{l}40-84 \\
(n=6) \\
20,23 \\
(n=2)\end{array}$ & $\begin{array}{l}58 \\
22\end{array}$ \\
\hline & Borderline $(n=6)$ & $5-35$ & 20 \\
\hline & Positive $(n=6)$ & $0-12$ & 2 \\
\hline $\begin{array}{l}\text { Terminal ileal resection } \\
\text { or inflammation }(n=6)\end{array}$ & $\begin{array}{l}\text { Borderline }(n=1) \\
\text { Positive }(n=5)\end{array}$ & $\begin{array}{l}1 \\
0\end{array}$ & $\begin{array}{l}1 \\
0\end{array}$ \\
\hline
\end{tabular}

this sample a day 5 retention of $36 \%$ was chosen provisionally as the SeHCAT-test lower limit of normal, whereas values between 30 and $35 \%$ were considered borderline. The results of the test in the three patients excluded as controls were, accordingly, interpreted as either positive (13\% retention in one) or borderline.

The term 'chronic diarrhoea' (Table 1) covered a wide clinical spectrum, as indicated by an asterisk in Table 2. This was reflected in the responses to both tests. On the basis of the limits adopted, the SeHCAT-test was positive in every case of ileopathy and of small gut excess luminal flow. The six cases of idiopathic bile acid diarrhoea (definition given previously) all had positive SeHCAT-tests and chronic watery diarrhoea which was relieved only by cholestyramine. With no malabsorption of fat and carbohydrates the 'allergic' diarrhoea subsided on total oral fasting and later on cromoglycate (Nalcrom), only to recur whenever this medication was withdrawn. Before treatment the SeHCAT-test was positive, probably reflecting rapid small gut transit. The case of surreptitious lipid overload was caused by a hidden intake of chocolate corresponding to about $250 \mathrm{~g}$ triglyceride fat per day (absorptive Tmax some $150 \mathrm{~g} /$ day). Under strict dietary control a severe steatorrhoea vanished, and simultaneously the SeHCAT- and breath tests became negative. On the basis of the clinical features the SeHCAT-test seems to be slightly more sensitive and not less specific than the breath test.

The reproducibility of counting ${ }^{75} \mathrm{Se}$ was evaluated from duplicate determinations where the second measurement took place when the patient had been ambulant for a couple of minutes. On day 0 the coefficient of variation was $1.2 \%$, on day 5 : $1 \cdot 4 \%$. Furthermore, two subjects were investigated twice (on two different doses of isotope), after an interval of three to six weeks. The day 5 retention percentages were 0 and $0 \%$ in one patient, and $43 \%$ and $44 \%$ in the other.

Finally, it may be mentioned that both isotopes have been measured simultaneously in the stool. The faecal excretion of ${ }^{75} \mathrm{Se}$ was between 1.7 and 10 times higher than that of ${ }^{14} \mathrm{C}$.

\section{Discussion}

The use of a gamma camera as an external counter of a region of interest (the abdomen) raises a number of problems. Certain features are desirable - namely, good precision of retention percentage measurements, independence of dead time effects, a low dosage of radiation to the patient, and as little influence as possible of isotope distribution and body build and positioning of the 
Table 2 Results of bile acid absorption tests in relation to disease $(n=33)$

\begin{tabular}{|c|c|c|c|}
\hline $\begin{array}{l}{\left[1-{ }^{14} \mathrm{C}\right] \text {-cholylglycine }} \\
\text { breath test }\end{array}$ & ${ }^{75} \mathrm{SeHCAT}$-test & Disease & $n$ \\
\hline Negative $(n=12)$ & $\begin{array}{l}\text { Negative }(n=10) \\
\text { Positive }(n=2)\end{array}$ & $\begin{array}{l}\text { Ulcerative colitis/ischaemic colitis } \\
\text { (without evidence of ileal damage) } \\
\text { Alternating diarrhoea and constipation } \\
\text { Postgastrectomy } \\
\text { Idiopathic bile acid diarrhoea }\end{array}$ & $\begin{array}{l}5^{*} \\
4^{*} \\
1^{*} \\
2^{*}\end{array}$ \\
\hline Borderline $(n=10)$ & $\begin{array}{l}\text { Borderline }(n=3) \\
\text { Positive }(n=7)\end{array}$ & $\begin{array}{l}\text { Controls } \\
\text { Ileal resection }(<5 \mathrm{~cm}) \\
\text { Control } \\
\text { Ileitis } \\
\text { Idiopathic bile acid diarrhoea } \\
\text { Allergic diarrhoea } \\
\text { Surreptitious magnesium abuse } \\
\text { Postgastrectomy }\end{array}$ & $\begin{array}{l}2 \\
1^{*} \\
1 \\
1^{*} \\
2^{*} \\
1^{*} \\
1^{*} \\
1^{*}\end{array}$ \\
\hline Positive $(n=11)$ & Positive $(n=11)$ & $\begin{array}{l}\text { Ileal resection or inflammation } \\
\text { Idiopathic bile acid diarrhoea } \\
\text { Secretory diarrhoea (apudoma) } \\
\text { Surreptitious lipid overload } \\
\quad \text { (some } 250 \mathrm{~g} \text { triglyceride fat per day) } \\
\text { Postgastrectomy dumping }\end{array}$ & $\begin{array}{l}6 \\
2^{*} \\
1^{*} \\
1^{*} \\
1^{*}\end{array}$ \\
\hline
\end{tabular}

* Denotes chronic diarrhoea in Table 1.

patient. These requirements are not all attainable and some of them tend, in fact, to be mutually exclusive. The only variables in our investigations were administered isotope dose and the distance between patient and gamma camera; and our procedure must, therefore, be regarded as a reasonable compromise. Our overall results are similar to those obtained by Merrick et al (unpublished observations) who used a clinical whole-body counter. They indicate that it is, indeed, possible to obtain results with an uncollimated gamma camera which are comparable with those found with a clinical whole-body counter. To what degree our results may deviate from those found with more sophisticated instrumentation is to be the subject of further investigation. From experiments on phantoms the worst possible deviations from a well-mixed isotope distribution may be simulated. Such experiments show that it would still be possible to detect patients with bile acid loss, but the technique needs further refinement in borderline cases.

Interpretation of the SeHCAT-test is mainly derived from comparison with the breath test, which is apparently the most sensitive assay of bile acid absorption available to the clinical routine. The two tests are based on different techniques and they have, in fact, been performed simultaneously.

The lower limit of normal adopted for the SeHCAT-test implies borderline results in two and a positive result in one out of the eight patients without gastrointestinal complaints. As the breath test was borderline in these three patients the interpretation of the SeHCAT-test has not been revised so far. It is unfortunate, however, that shortage of SeHCAT prevented re-examination of the patient with the positive test. As regards the 20 patients with chronic diarrhoea the outcome of both tests is often in agreement. Where discrepancies occur, with negative or borderline breath tests and positive SeHCAT-tests, the latter test is apparently the more reliable when judged from the final diagnoses (Table 2). As regards the breath test, measurement of faecal radioactivity is essential for the evaluation of bile acid absorption. In $\left[1-{ }^{14} \mathrm{C}\right]-$ cholylglycine the label is in the glycine moiety. When not absorbed in the small gut the tracer is exposed to bacterial deconjugation in the colon; there is then release of the absorbable aminoacid which is partly metabolised to ${ }^{14} \mathrm{CO}_{2}$ and exhaled. In this way faecal radioactivity is the result of a competition between colonic absorption and faecal excretion of ${ }^{14} \mathrm{C}$. In contrast, the SeHCAT label is in the bile acid analogue and will stay here despite bacterial degradation of the compound. The difference between the two tracers is reflected in the higher faecal excretion of ${ }^{75} \mathrm{Se}$ as compared with ${ }^{14} \mathrm{C}$ as mentioned under 'Results', and this again may perhaps explain why the breath test is the less sensitive of the two assays. 
In brief, it is our preliminary experience that the SeHCAT-test competes favourably with the breath test where detection of bile acid malabsorption is concerned. The external counting can be performed with equipment available in most larger hospitals.

We thank Amersham International Ltd for free supply of ${ }^{75} \mathrm{Se} 23$-selena-25-homocholic acid. This work was supported by grants to E $\mathrm{H}$ Thaysen from the P Carl Pedersen Foundation and the Aalborg Municipal Foundation for Medical Research.

\section{References}

1 Thaysen EH, Pedersen L. Idiopathic bile acid catharsis Gut 1976; 17: 965-70.

2 Fromm H, Thomas PJ, Hofmann AF. Sensitivity and specificity in tests of distal ileal function: a prospective comparison of bile acid and vitamin $\mathrm{B}_{12}$ absorption in ileal resection patients. Gastroenterology 1973; 64: 1077-90.

3 Thaysen EH. Diagnostic value of the ${ }^{14} \mathrm{C}$-cholylglycine breath test. Clin Gastroenterol 1977; 6: 227-45.

4 Hofmann AF. Beaumont prize acceptance speech. Gastroenterology 1979; 77: 955-66.

5 Boyd GS, Merrick MV, Monks R, Thomas IL. ${ }^{75}$-Se labelled bile acid analogues. New radiopharmaceuticals for investigating the enterohepatic circulation. $\mathrm{J}$ Nucl Med 1981; 22: 720-25.

6 Fromm H, Hofmann AF. Breat test for altered bile acid metabolism. Lancet 1971; 2: 621-5. 